\title{
Effects of Aging on Chlorinated Plasma Polymers
}

\author{
Rafael Gustavo Turria, Milena Kowalczuk Manosso Amorim ${ }^{a}$, Tayan Vieira Hadich ${ }^{a}$
} Isabela Cristina Fernandes ${ }^{a}$, Gabriel Ferreira Fernandes ${ }^{a}$, Diego Rossi $^{a}$, Elidiane Cipriano Rangel ${ }^{a}$,

\author{
Steven Frederick Durrant ${ }^{*}$ * \\ ${ }^{a}$ Laboratório de Plasmas Tecnológicos, Instituto de Ciência e Tecnologia de Sorocaba, Universidade \\ Estadual Paulista - UNESP, Avenida Três de Marco, 511, \\ Alto da Boa Vista, 18087-180, Sorocaba, SP, Brazil
}

Received: September 14, 2016; Revised: November 21, 2016; Accepted: January 03, 2017

\begin{abstract}
Thin films deposited from propanol-chloroform-argon mixtures by plasma enhanced chemical vapor deposition at different partial pressures of chloroform in the feed, $\mathrm{C}_{\mathrm{Cl}}$, were characterized after two years of aging and their characteristics compared with their as-deposited properties. Film thickness decreased and surface roughness increased with aging. Surface contact angles also increased with aging for the chlorinated films. For the film deposited with $40 \%$ chloroform in the feed the contact angle increased about $14^{\circ}$. Transmission infrared and Energy dispersive X-ray spectroscopy revealed that the films gain carbonyl and hydroxyl groups and lose chlorine and hydrogen on aging. Chlorination appears to make the films more durable. Delamination was observed for the unchlorinated films.
\end{abstract}

Keywords: thin films; a-C:H:O:Cl; IRS; stability; contact angle

\section{Introduction}

Although some studies have been made on amorphous hydrogenated carbon films containing chlorine $\mathrm{e}^{1-3}$ there is still a relative dearth of literature dealing with such materials. Here, a-C:H:O:Cl films deposited from plasmas fed propanol, chloroform and $\operatorname{argon}^{1}$ and aged for two years are characterized to investigate any morphological, structural and compositional changes.

In the present investigation, film thickness and surface roughness were studied using Profilometry. Surface contact angles were measured using goniometry. Chemical structure and composition are examined using Transmission infrared spectroscopy and Energy dispersive X-ray spectroscopy, respectively. Surface features of the aged films were examined using Scanning electron microscopy.

\section{Experimental}

\subsection{Film Production}

Details of the depositions are given in the literature ${ }^{1}$. In brief, films were produced by the PECVD of propanolchloroform-argon mixtures at constant total pressure, and partial pressures of chloroform of 0 to $40 \%$. As the proportion of chloroform in the feed was increased the proportion of argon was correspondingly decreased.

\subsection{Characterizations}

Film thickness was measured using a profilometer on samples deposited onto smooth glass plates containing a

\footnotetext{
* e-mail: steve@sorocaba.unesp.br
}

film step-height delineated during the deposition process with the aid of a mask. Nine horizontal scans of $2000 \mu \mathrm{m}$ length obtained with a Veeco Dektak 150 profilometer were taken. Surface roughness, $\mathrm{R}_{\mathrm{a}}$, was calculated from these data for each film.

Surface wettability was determined from contact angle $(\theta)$ data taken using a Ramé-Hart 100 goniometer. These measurements were conducted immediately after deposition and two years later. The samples were stored for ageing under ambient atmospheric conditions for two years. Three drops of deionized water $(0.2 \mu \mathrm{L})$ were deposited on different regions of the sample surface and the contact angle was measured 10 times on each side of the drop, resulting in sixty $\theta$ values per sample.

A Jasco FTIR-410 spectrophotometer was used for transmission infrared spectroscopy in the 4000 to $400 \mathrm{~cm}^{-1}$ range. Each spectrum comprised 128 scans; a resolution of $4 \mathrm{~cm}^{-1}$ was achieved.

Images of the aged films were obtained using a Jeol JSM-6010LA scanning electron microscope equipped with a secondary electron detector. Chemical composition of the aged films was studied using EDS.

\section{Results and Discussion}

Figure 1 shows the film thickness as a function of the percentage of chloroform in the feed, $\mathrm{C}_{\mathrm{Cl}}$. The aged films tend to be thinner perhaps owing to the loss of chlorine as discussed below. Decreases of around 10\% have been observed in the aging (-40 days) of a-C:H:O films (where a-prefix indicates 


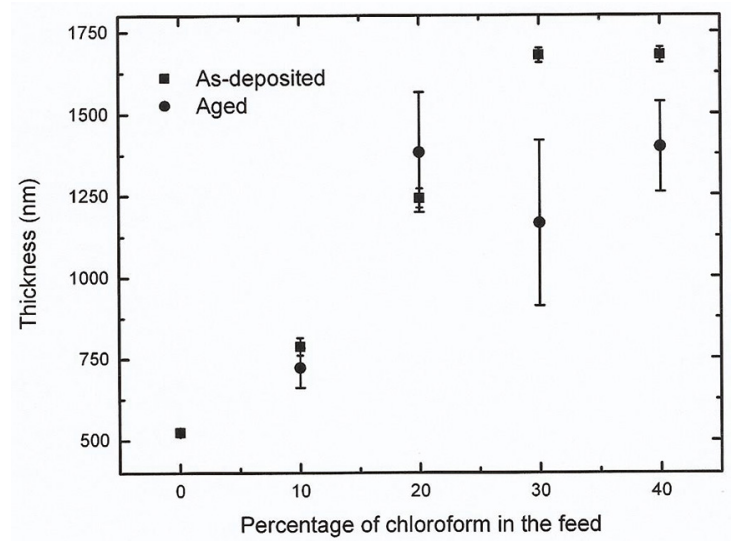

Figure 1: Film thickness as a function of $\mathrm{C}_{\mathrm{Cl}}$ for the as-deposited and aged films.

amorphous) produced from acetone plasmas ${ }^{4}$. Apart for the absence of chlorine, these films have chemical compositions similar to the films examined in the present study. For the most chlorinated films in the present study, which were obtained at $\mathrm{C}_{\mathrm{C}}$ of $30 \%$ and $40 \%$, the relative thickness decreases were roughly $30 \%$ and $13 \%$, respectively. The condition of the aged unchlorinated film prevented its thickness from being reliably measured. However, the film deposited at $\mathrm{C}_{\mathrm{Cl}}=10 \%$, and therefore having very low chlorine content, suffered a decrease in thickness of around $8 \%$, compatible with the value of $10 \%$ cited above for a-C:H:O films.

Figure 2 shows the surface roughness, $R_{a}$, as a function of $\mathrm{C}_{\mathrm{Cl}}$. The aged films are consistently and considerable rougher than the as-deposited material, $\mathrm{R}_{\mathrm{a}}$ increasing from around $50 \mathrm{~nm}$ to more than $200 \mathrm{~nm}$ for the aged films. This may be due to the strong de-chlorination and increase in oxygen-containing functionalities as revealed by the infrared and elemental analyses discussed below. (The roughness of the unchlorinated film could not be reliably measured.)

Figure 3 shows the surface contact angle as a function of $\mathrm{C}_{\mathrm{Cl}}$. There is a clear tendency to greater contact angles with aging for the originally more chlorinated films. For the film deposited at a $\mathrm{C}_{\mathrm{Cl}}$ of $40 \%$, the surface contact angle increases from $\sim 72^{\circ}$ to $\sim 86^{\circ}$. The increase in the presence of polar oxygen-containing groups with aging would be expected to decrease the contact angle but the considerable increase in roughness (Figure 2) tends to increase it. The magnitude of the contact angle is similar to those obtained for a-C:H:Cl films containing considerably more chlorine ( $\sim 5$ at.\%), for which the contact angles were about $77^{\circ} 2$.

Figure 4 shows transmittance spectra of pairs of films (as-deposited and aged) produced at $\mathrm{C}_{\mathrm{Cl}}$ (percentage of chloroform in the feed) of $0,10,20,30$ and 40 . All spectra show absorptions at 2950,2900 and $2850 \mathrm{~cm}^{-1}$, respectively, due to $\mathrm{CH}, \mathrm{CH}_{2}$ and $\mathrm{CH}_{3}$. Similarly, owing to $\mathrm{CH}_{2}$ and $\mathrm{CH}_{3}$ groups, all the spectra show absorptions centered around

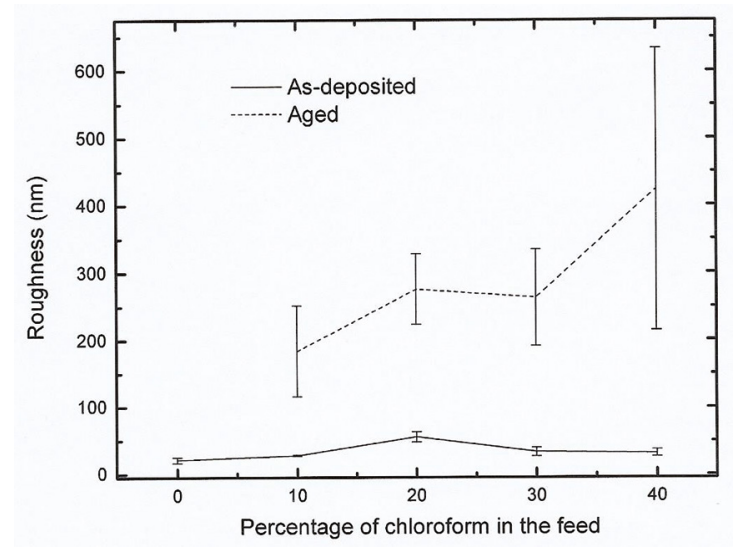

Figure 2: Surface roughness as a function of $\mathrm{C}_{\mathrm{Cl}}$ for the as-deposited and aged films.

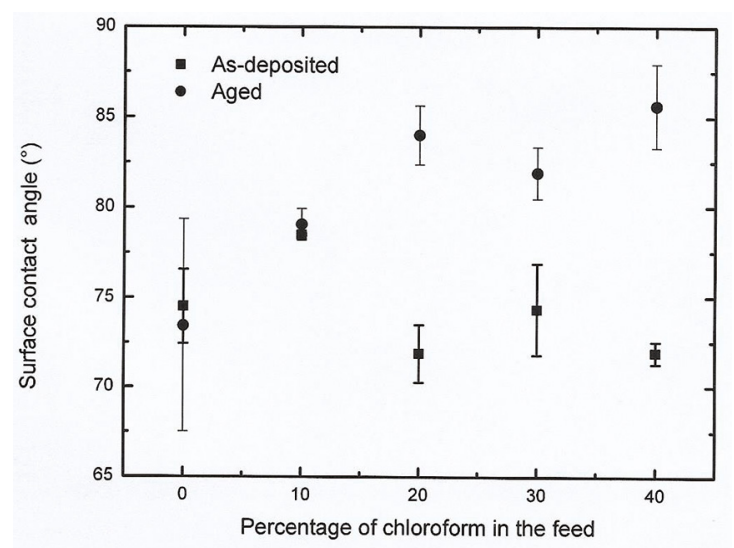

Figure 3: Surface contact angle as a function of $\mathrm{C}_{\mathrm{Cl}}$ for the asdeposited and aged films.

1450 and $1380 \mathrm{~cm}^{-1}$. All spectra also exhibit a characteristic absorption at around $1700 \mathrm{~cm}^{-1}$, attributed to the presence of stretching in $\mathrm{C}=\mathrm{O}$ groups. Inspection of Figure 4 reveals that the peak heights of the absorptions due to $\mathrm{C}=\mathrm{O}$ increase in the aged films compared to the peaks due to $\mathrm{CH}_{x}$.

The spectra of the aged chlorinated films show a clear absorption at $\sim 1080 \mathrm{~cm}^{-1}$ due to -C-O groups in a primary alcohol. The peak heights of the $-\mathrm{C}-\mathrm{O}$ absorption tend to increase compared to those due to $\mathrm{CH}_{\mathrm{x}}$ as the proportion of chloroform in the feed increases.

An absorption at $\sim 3500 \mathrm{~cm}^{-1}$, attributed to the presence of hydroxyl groups, increases as $\mathrm{C}_{\mathrm{Cl}}$ increases, and also tends to be greater for the aged sample in each sample pair.

Aging causes the incorporation of oxygen as $\mathrm{C}-\mathrm{O}$ and $\mathrm{C}=\mathrm{O}$, and also of $\mathrm{OH}$ groups. This is typical of plasma polymers, which on deposition usually have a high density of free-radicals that react with oxygen and water vapor ${ }^{5,6}$ when exposed to ambient conditions. Thus carbonyl and hydroxyl groups are produced ${ }^{7}$. Although this process can 


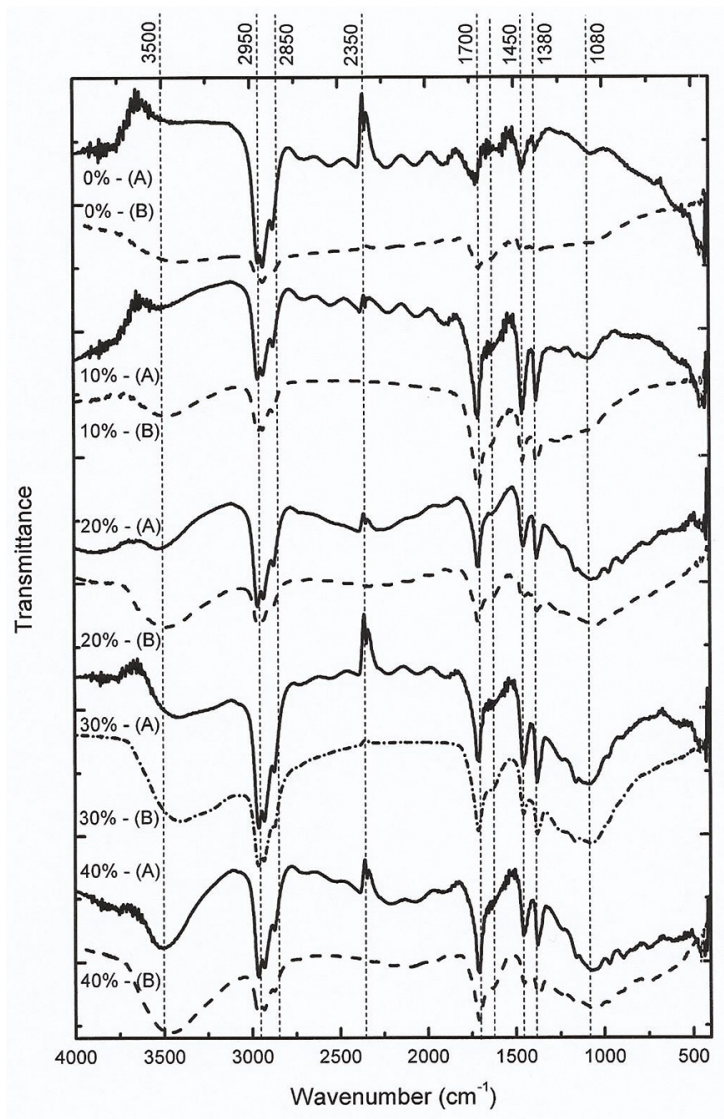

Figure 4: Transmission infrared spectra in the 400 to $4000 \mathrm{~cm}^{-1}$ range of pairs of films, (A) as-deposited, (B) aged, as a function of $\mathrm{C}_{\mathrm{Cl}}$.

occur in seconds, it can apparently also continue slowly thereafter on a scale of months or years.

A shoulder to the lower frequency side of the 1700 $\mathrm{cm}^{-1}$ peak (at $\sim 1650 \mathrm{~cm}^{-1}$ ) is more clearly visible in the aged films, and is attributed to the presence of $\mathrm{C}=\mathrm{C}$ bonds, which are not present in molecules of the monomers or comonomers (propanol and chloroform). These likely result from dehydrochlorination, which is known to occur in the aging of conventional poly(vinyl) chloride ${ }^{8}$.
Table 1 shows the elemental compositions ( $\mathrm{C}, \mathrm{O}, \mathrm{Si}$ and $\mathrm{Cl}$ ) of the original and aged films as determined by XPS and EDS, respectively. The latter analyses are more characteristic of the bulk compositions. The concentration of oxygen at the surface of the original films is typically higher than in the bulk. Hence the lower concentrations registered for oxygen of the aged films reflect this fact. The infrared spectra discussed above indicate a relative increase in oxygen-containing functionalities upon aging. Chlorine, which is dispersed in the bulk, is clearly lost with aging.

The aged unchlorinated film showed signs of delamination and appeared to dissolve when exposed to water droplets. A tiny contamination with $\mathrm{Si}$, possibly present in the substrate, was observed for this film.

Scanning electron micrographs of the aged films are shown in Figure 5 (a to e). The surface of the aged film deposited without chloroform (Figure 5a) appears irregular and particulate material is present. In Figure $5 \mathrm{c}$ spherical particulate matter with a range of diameters of $1 \mu \mathrm{m}$ or less is observed. On the same scale the films grown at the highest $\mathrm{C}_{\mathrm{Cl}}$ (Figures. 5d and 5e) appear more uniform. Visually the unchlorinated film showed some delamination and the more chlorinated films a more uniform coverage.

\section{Conclusions}

On aging over two years under ambient conditions, chlorinated amorphous plasma films are oxidized, possess greater densities of $\mathrm{OH}, \mathrm{C}-\mathrm{O}, \mathrm{C}=\mathrm{O}$ and $\mathrm{C}=\mathrm{C}$ bonds, and suffer dehydrochlorination. In addition, film thickness decreases while surface roughness and the surface contact angle increases. The chlorinated films tend to be more stable, resistant to delamination, and present a more uniform aspect in electron microscopy images.

\section{Acknowledgements}

The authors thank FAPESP (2014/21594-9) and CNPq for financial support. Two of us (TVH and ICF) acknowledge support from UNESP (Bolsa Reitoria).

Table 1. Elemental composition (at.\%) as a function of $\mathrm{C}_{\mathrm{Cl}}$, the percentage of chloroform in the feed, for the as-deposited and aged films. Data for as-deposited films were previously published in eff $^{1}$.

\begin{tabular}{lcccccccc}
\hline $\begin{array}{l}\text { Element } \\
\mathrm{C}_{\mathrm{Cl}}(\%)\end{array}$ & As-deposited & Aged & As-deposited & Aged & As-deposited & Aged & As-deposited & Aged \\
\hline 0 & 88.7 & 90.4 & 11.3 & 8.1 & -- & 1.3 & - & - \\
10 & 82.2 & 90.6 & 11.1 & 9.1 & -- & 0.04 & 2.7 & 0.3 \\
20 & 81.4 & 88.9 & 12.4 & 10.1 & -- & -- & 6.3 & 1.0 \\
30 & 80.2 & 88.9 & 12.2 & 8.4 & -- & -- & 7.6 & 2.7 \\
40 & 80.0 & 91.7 & 12.3 & 8.2 & -- & -- & 7.7 & 0.2 \\
\hline
\end{tabular}



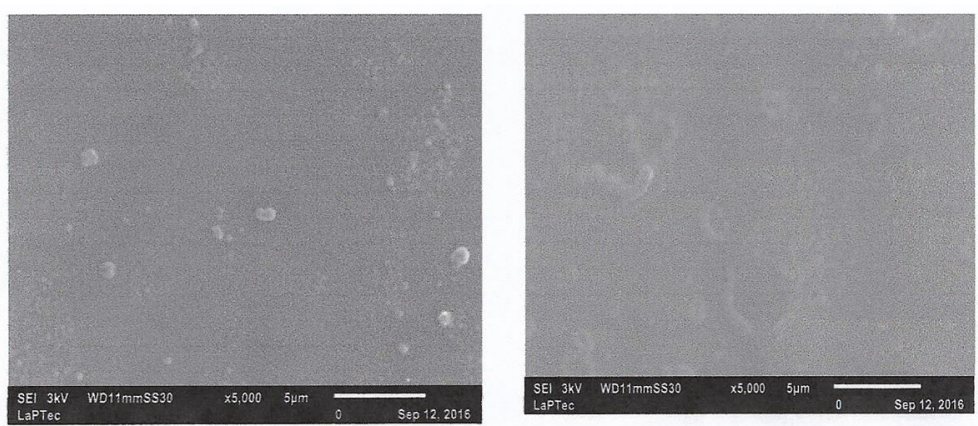

(a)

(b)

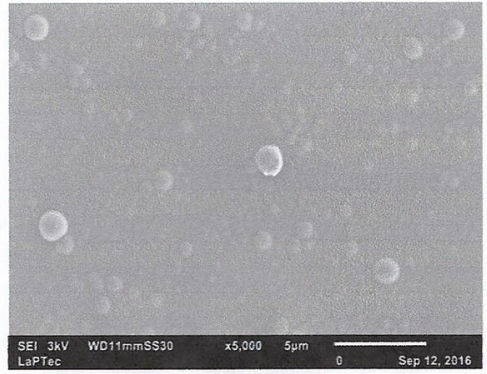

(c)

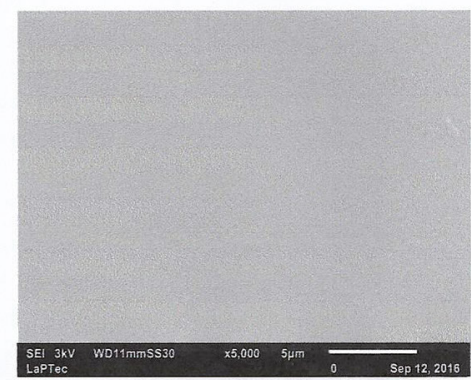

(d)

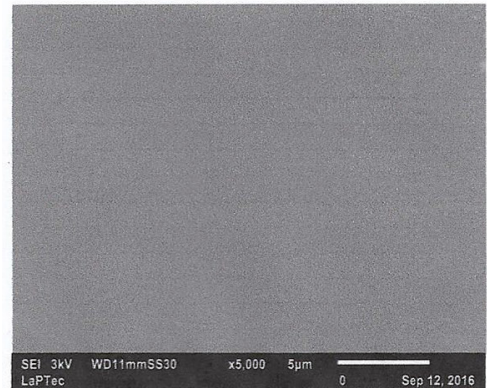

(e)

Figure 5: Scanning electron microscopy images of the aged films at $\mathrm{C}_{\mathrm{Cl}}$ values of (a) $0 \%$, (b) $10 \%$, (c) $20 \%$, (d) $30 \%$, (e) $40 \%$.

\section{References}

1. Rossi D, Schreiner WH, Durrant SF. Characterization of amorphous hydrogenated chlorinated plasma polymers. Surface and Coatings Technology. 2016;289:118-223.

2. Turri R, Davanzo CU, Schreiner W, Silva JHD, Appolinario MB, Durrant SF. Structural and optical properties of chlorinated plasma polymers. Thin Solid Films. 2011;520(5):1442-1445.

3. Turri RG, Santos RM, Rangel EC, da Cruz NC, Bortoleto JRR, Silva JHD, et al. Optical, mechanical and surface properties of amorphous carbonaceous thin films obtained by plasma enhanced chemical vapor deposition and plasma immersion ion implantation and deposition. Applied Surface Science. 2013;280:474-481.

4. Drabik M, Celma C, Kousal J, Biederman H, Hegemann D. Properies of a-C:H:O plasma polymer films deposited from acetone vapors. Thin Solid Films. 2014;573:27-32.
5. Morosoff N, Crist B, Bumgarner M, Hsu T, Yasuda H. Free Radicals Resulting from Plasma Polymerization and Plasma Treatment. Journal of Macromolecular Science: Part A Chemistry. 1976;10(3):451-471.

6. Yasuda H, Bumgarner MO, Marsh HC, Morosoff N. Plasma polymerization of some organic compounds and properties of the polymers. Journal of Polymer Science Part A: Polymer Chemistry. 1976;14(1):195-224.

7. Stundžia V, Bílková P, Biederman H, Slavínská D, Hlídek P. Electrical properties of plasma-polymerized C:H films. Vacuum. 1998;50(1-2):23-25.

8. Quennehen P, Royaud I, Seytre G, Gain O, Rain P, Espilit T, et al. Determination of the aging mechanism of single core cables with PVC insulation. Polymer Degradation and Stability. 2015;119:96-104. 